Revista lus et Praxis, Año 22, No 2, 2016, pp. 299 - 330

ISSN 0717 - 2877

Universidad de Talca - Facultad de Ciencias Jurídicas y Sociales

La resolución judicial de los conflictos contractuales:

La actividad de los jueces a la luz de los principios y objetivos dentro del Derecho español

M. Isabel Garrido Gómez

Trabajo recibido el 14 de febrero y aprobado el 29 de diciembre de 2015

\title{
La resolución judicial de los conflictos contractuales: La actividad de los jueces a la luz de los principios y objetivos dentro del Derecho español ${ }^{*}$
}

\author{
THE JUDICIAL SETTLEMENT OF CONTRACTUAL CONFLICT: THE ACTIVITY OF \\ JUDGES IN THE LIGHT OF THE PRINCIPLES AND OBJECTIVES IN SPANISH LAW
}

\section{Isabel Garrido Gómez ${ }^{* *}$}

\begin{abstract}
RESUMEN
El tema objeto de estudio consiste en analizar ciertos aspectos de las resoluciones judiciales que dirimen conflictos contractuales. La razón por la que se ha elegido esta cuestión es por la gran cantidad de relaciones jurídicas privadas que se refieren a las obligaciones bilaterales, a lo que se suma el hecho de que, si observamos la realidad, enseguida se aprecia la existencia de un absoluto predominio numérico de los litigios cuya causa principal consiste en su incumplimiento. Esa situación se agrava al tomar conciencia de la falta de una regulación completa y sistemática, junto a la evidente inadecuación normativa a las exigencias del tráfico jurídico.

La reflexión se acota dentro de los contratos bilaterales regulados por el Derecho común español, con alguna referencia al Derecho italiano, omitiendo las obligaciones bilaterales mercantiles y el ámbito de los ordenamientos forales, dada la excesiva extensión que ello supondría.
\end{abstract}

ABSTRACT

The aim of the study is to analyze certain aspects of judicial decisions in settlement of contractual disputes. The reason why this issue has been chosen is the large number of private legal relations that refer to bilateral obligations, together with the fact that in practice litigation arising chiefly from non-compliance is overwhelmingly predominant in quantitative terms. This situation is aggravated by the absence of any complete and systematic regulation and by the patently inadequate fit of legislation to the requirements of legal transactions.

This article is limited to the reflection about bilateral contracts regulated by Spanish common law with some reference to Italian law. For reasons of space, it omits commercial bilateral obligations and the field of regional jurisdictions.

Palabras Clave

Contratos, Conflictos, Resoluciones judiciales, Principios, Objetivos

KEYWORDS

Contracts, Conflicts, Judicial decisions, Principles, Objectives

\footnotetext{
* Este trabajo ha sido realizado en el marco del Proyecto "Derechos humanos, sociedades multiculturales y conflictos" (DER 2012-31771) del Ministerio de Economía y Competitividad de España.

** Profesora Titular de Filosofía del Derecho, Departamento de Ciencias jurídicas, Facultad de Derecho, Universidad de Alcalá (España). Correo electrónico: misabel.garrido@uah.es.
} 


\section{Introducción: Las obligaciones bilaterales como objeto de las controversias analizadas}

En relación al objeto de las controversias que serán analizadas a lo largo del presente trabajo, conviene comenzar por hacer una somera alusión a la etimología del término "obligación", el cual viene de la palabra latina obligatio y ésta, a su vez, lo hace de obligare (ob, "a causa de", y ligare, "ligar" o "atar"). Significa, por tanto, "ligadura", "sujeción física", "lazo de unión", "vínculo por causa de algo". La voz enunciada es uno de los vocablos que forman el substratum del orden jurídico y, en general, de todas las ciencias sociales, por lo que se hace precisa la delimitación de la obligación jurídico-privada, que es la que verdaderamente nos interesa, de las demás acepciones. Sin duda, desde el punto de vista doctrinal el concepto de "obligación" en el Derecho romano ha servido de modelo para su elaboración a los autores modernos, siendo ineludible el tratamiento de las dos definiciones de obligatio legadas por las fuentes romanas.

La primera, "la obligación es un vínculo de Derecho, por el que somos constreñidos con la necesidad de pagar alguna cosa según las leyes de nuestra ciudad", aparece en las Instituciones de Justiniano y hay una gran disputa en torno a su atribución, ya que unos lo hacen a Florentino, los más, y otros a Justiniano. La expresión solvendae rei hay que entenderla con la amplitud de cualquier prestación. Las palabras cura nostrae civitatis aluden al ius civile o al ius populiromani, en contraposición al ius gentium ${ }^{1}$. El segundo concepto, que se incluye en el Digesto, se debe a Paulo. Se trata de una formulación de las características que diferencian las obligaciones del derecho real, describiendo con más precisión que la anterior el contenido y el objeto del vínculo obligatorio: "la sustancia de las obligaciones no consiste en que se haga nuestra alguna cosa corpórea o una servidumbre, sino en que se constriñe a otro a darnos, a hacernos o a prestarnos alguna cosa" ${ }^{2}$.

Con estas definiciones que suprimen la última parte inserta en las Instituciones al recoger las aportaciones de los juristas del Derecho intermedio y se cuidan de perfilar los términos con la eliminación de la alusión al Derecho civil de los romanos y con la mejor formación del contenido de la prestación, se formó una definición más racional que el tiempo ha ido conservando y aceptando: "la obligación es un vínculo de derecho por el que somos constreñidos con la necesidad de dar, hacer o prestar alguna cosa".

\footnotetext{
1 Albaladejo (1980), pp. 316 y ss.; Chabas (1966), p. 2026; Lacruz (2013), pp. 300 y 301.

2 Digesto, 44, 7, 3. Albertario (1936), pp. 1 y ss.; Hattenhauer (1987), pp. 83 y ss.; Rampelberg (2000), pp. 51 y ss.
} 
Dicha alusión al Derecho romano es importante por el acogimiento que de él hacen las corrientes doctrinales modernas, lo cual no quiere decir que no se haya introducido ninguna innovación con el fin de otorgar a la figura una elaboración lo más perfecta posible. Tales cambios han sido tres. El primero, sustituye la palabra "vínculo" por la de "relación" -ofrecida por Savigny-en casi todos los casos, de manera que la obligación es una relación jurídica (obligatoria), cauce para que las personas realicen actividades de cooperación social $y$, peculiarmente, para que les sea posible intercambiar bienes y servicios. Sin embargo, no todas las posturas son desenvueltas de forma uniforme. Destaca una postura amplia, comprensiva de la relación jurídica total, defendida por Albaladejo, Díez-Picazo, Gullón, Díaz Pairó, Giorgianni y Ruggiero, entre otros. Otras posiciones son las centradas en el lado positivo de la relación obligatoria, en la necesidad en que se constituye el deudor como consecuencia de ella, este grupo lo representan, por ejemplo, Sánchez Román, Colin y Capitant, y von Thur. $Y$ la que posee un sentido que se refiere a su naturaleza activa, dentro de una visión parcial, caso de Clemente de Diego o de Enneccerus ${ }^{3}$.

El segundo aspecto recae en otorgar mayor importancia al elemento objetivo o patrimonial de la relación obligatoria, en lugar de al subjetivo o personal, originario de las Instituciones justinianeas. Se presenta el derecho del acreedor más como una facultad de exigir del deudor una actividad, como un poder de adentrarse en el patrimonio del deudor para obtener su satisfacción, si es que la otra parte incumple; éste es el ideario de Brinz, Demogue o Polacco... Mas, algunos autores, supuesto de Arias Ramos y Ruggiero, no quieren desprenderse del criterio clásico y adoptan una postura mixta. La obligación se compone, según ellos, de un elemento personalista y de otro objetivo.

La tercera reflexión resalta la índole jurídico-privada de la obligación propiamente dicha, debido a que no toda prestación integra el objeto de la relación obligatoria. Se han de excluir los deberes desprendidos de un orden general de relaciones de Derecho preestablecidas, línea en la que se pronuncian Dernburg, Díaz Pairó y Sánchez Román, quienes apuntan como notas de las relaciones más eventuales y transitorias, denominadas voluntarias o contractuales, y con más exactitud patrimoniales: representar un interés privado, constituir vínculos de naturaleza transitoria y poder hacerse efectivos en caso de incumplimiento por un equivalente económico obtenido del patrimonio del deudor ${ }^{4}$.

3 Albaladejo (1980), p. 15; Coing (1996), pp. 497 y ss.; Díez-Picazo y Gullón (2012), pp. 119 y ss.; Díaz (1948), p. 12; GIORGIANnI (1958), p. 135; RUGGiero (1929), p. 7. En cuanto al concepto de "obligación" como relación jurídica, ver SAviGnY (2005), párrafo 4.

4 Tettenborn (1984), pp. 1 y ss. Y, en general, Coing (1951), pp. 22 y ss.; Puig (1999), pp. 26 y 27. 
En conclusión, si recogemos todas las aportaciones innovadoras de las escuelas modernas a la teoría de la obligación, de acuerdo con una posición intermedia entre el objetivismo y el subjetivismo, desembocamos en el concepto de: "la relación jurídica que permite a una persona, denominada acreedor, el exigir a otra, Ilamada deudor, para satisfacer un interés privado digno de protección, determinada prestación garantizada con todo el activo patrimonial del obligado en caso de incumplimiento".

Pero decíamos en un principio que, dentro del campo de las obligaciones, las que nos interesan son las recíprocas. Significando ellas lo siguiente:

- Que las pertenecientes a ambas partes deriven de un título unitario y común. No quedan ligados por una obligación específicamente bilateral quienes sean acreedores y deudores entre sí por coincidir derechos de crédito nacidos de figuras jurídicas independientes, como cuando "A puede ser acreedor de B en 1.000 pesetas a razón de un préstamo, y después el primero resulta ser deudor del segundo por daños causados en su propiedad".

- La existencia de una pluralidad de vínculos. En caso contrario se formaría una obligación unilateral, o relación establecida entre dos personas, de las cuales una ostenta solamente derechos y la otra, deberes correlativos a tales derechos. Al existir un vínculo jurídico obligatorio, una persona se obliga respecto de otra, sin que ella asuma ninguna obligación.

- Que todas las obligaciones sean las unas causas de las otras y se entrelacen los vínculos de manera que se establezcan prestaciones a cargo de cada una de las partes y que las prestaciones estén condicionadas.

- Que nazcan las obligaciones produciéndose la reciprocidad en el cumplimiento, de modo que se constituyan cada parte en acreedora y deudora a la vez de la contraria.

- Que cada prestación haya sido querida en equivalencia de la otra, lo cual se relaciona con la idea de la causa. Esta figura ha ido especializándose como medio de delimitar la esfera de la autonomía de la voluntad y evitar que la protección jurídica se ponga al servicio de algo que repugna a la conciencia social ${ }^{5}$.

Para dar una visión más clarificadora y completa de la delimitación conceptual investigada es conveniente discernir en la estructura de la bilateralidad una serie de nociones conformadoras de otras que están muy próximas, pero que permanecen en un plano ajeno y han sido mal interpretadas y valoradas en ciertos momentos como parte de tal sistema estructural ${ }^{6}$. A estos efectos, Alonso Pérez y Vattier Fuenzalida distinguen entre la bilateralidad "formal" (o

5 Ver, en general, los civilistas citados hasta ahora y, en especial, Атіraн (2005), pp. 24 y ss.

6 Según el esquema y la exposición hecha por VAtTier (1986), pp. 34 y ss. Ver también Pérez (1967), pp. 10 y ss. 
"actual") y "material" (o "potencial"). El primer aspecto surge explícitamente de los actos declarativos; el segundo lo hace implícitamente de los intereses afectados. La bilateralidad "formal" se refiere al número de declaraciones de voluntad que han concurrido a su formación y perfeccionamiento, y, desde un punto de vista causal, lo puede ser cuando son dos las declaraciones que concurren a su formación, por lo que es designable como bilateralidad "subjetiva", "genérica", "terminológica" o "genética", de "índole cuantitativa". En cambio, la "material" se refiere al contenido obligatorio y tiene naturaleza efectiva si genera obligaciones bilaterales a cargo de cada una de las partes obligadas. Su designación suele ser la de "objetiva", "específica", "sustantiva", "ejecutiva", de "naturaleza cualitativa"7.

En relación con la causa de la bilateralidad, dos corrientes fundamentales son las que destacan para establecer la causa de las relaciones jurídicas bilaterales: la tradicional, que indaga la ratio o justificación causal de las obligaciones engendradas (la causa de la obligación), y la más moderna, que sitúa la causa en el momento en que tiene lugar el desplazamiento patrimonial a que el precepto legal o el acuerdo de las partes se encamina (causa de atribución), teniendo en común la ausencia de una idea nítida de la bilateralidad que engloba los elementos de la onerosidad. Se cree que la causa de la bilateralidad debe integrar una noción unitaria y permanente, para ello es necesario tener en cuenta que estas relaciones jurídicas suponen obligaciones correlativas y que la obligación es un vínculo que liga a un comportamiento (prestación), fijándose dicho comportamiento en un contenido patrimonial. La causa analizada se agotaría en la idea de correlación ${ }^{8}$.

Si bien no hay que olvidar que existe una tendencia hacia la resolución extrajudicial de estos conflictos en España y en los textos internacionales básicos para la armonización del Derecho contractual europeo, de manera que la parte que ha sido víctima del incumplimiento solicita a la que ha incumplido la resolución del contrato, acudiendo al juez subsidiariamente cuando la contraparte no la acepta e inicia un procedimiento judicial para que se decida sobre si la solicitud extrajudicial tiene o no fundamento ${ }^{9}$; el artículo que nos interesa sobre todo es el 1.124 del Código Civil español, el cual establece que "la facultad de resolver las obligaciones se entiende implícita en las recíprocas para el caso de que uno de los obligados no cumpliese lo que le incumbe". Con lo que se mantiene un derecho de resolución concedido a la parte cumplidora, para dejar sin efecto una

\footnotetext{
7 Pérez (1967), p. 48; Vattier (1980), pp. 242 y ss.

8 Colin y Capitant (1960), pp. 450 y ss.; Dualde (1949), p. 89.

9 Ver a título ilustrativo las de obras de Clemente (2011); Díez-Picazo (2005); Díez-Picazo et al. (2002); San Miguel (2003), (2011a), (2011b).
} 
relación jurídica productora de obligaciones recíprocas ante el incumplimiento del otro obligado, sobreentendiendo que no tiene nada que ver con el pacto comisorio ni con la condición resolutoria expresa, porque en el contenido descrito del artículo 1.124 la voluntad de las partes no interviene para su admisión, es la ley la que fija las condiciones necesarias para su ejercicio ${ }^{10}$.

El artículo 1.124 del Código Civil en su párrafo segundo prescribe: "El perjudicado podrá escoger entre exigir el cumplimiento o la resolución de la obligación, con el resarcimiento de daños y abono de intereses en ambos casos. También podrá pedir la resolución, aun después de haber optado por el cumplimiento, cuando éste resultare imposible". Con lo cual se ahonda en la índole opcional de la acción de resolución. Se facultará para que si la obligación se incumple a causa de una situación plenamente antijurídica, verificadora de un ataque al orden del Derecho consagrado directamente en la norma o proyectado de manera convencional, pueda solicitar el perjudicado el cumplimiento de la obligación o su resolución como mecanismos para que la situación sea modificada ${ }^{11}$.

En aplicación de la doctrina general, la indemnización pertinente no va ineludiblemente ligada al incumplimiento. El acreedor tiene que haber sufrido efectivamente los daños y probar (damnum emergens) los perjuicios (lucrum cessans) surgidos, de cualquier naturaleza que sean, "materiales" o "morales", teniendo que mediar una relación causa-efecto con la culpa o negligencia de la parte deudora. El juez deberá fijar la cuantía correspondiente en la sentencia $\mathrm{o}$, al menos, establecer los parámetros con arreglo a los que haya que hacer la liquidación según su libre convicción. Cuando no sea posible ninguna de las dos cosas, se concretará en fase de ejecución (art. 571 y ss. de la Ley de Enjuiciamiento Civil) ${ }^{12}$.

Acto seguido, en el análisis del artículo 1.124 del Código Civil, su párrafo tercero dictamina que "el Tribunal decretará la resolución que se reclama, al no haber causas justificadas que le autoricen para señalar plazo". Tal regulación está en consonancia con la búsqueda del equilibrio y la equidad que debe

\footnotetext{
10 Álvarez (2009), pp. 70 y ss.; Cristóbal (1989), pp. 13 y ss.; González (1987), pp. 191 y ss., y en general ver Dírz-PICAzo (2005). Ver Sentencias del Tribunal Supremo de España (Sala 1. ${ }^{\mathrm{a}}$ ) de 31 de mayo de 2002, 19 de enero de 2005, 23 de mayo de 2005, 7 de febrero de 2013 y 3 de julio de 2013.

11 Ver sobre la naturaleza opcional del artículo 1.124 del Código Civil: Dírz-Pıcazo (2005), pp. 15-20; Espinar (1969), p. 143; Gómez (2007), pp. 15-32; San Miguel (2003), pp. 25-35. Ver las Sentencias del Tribunal Supremo de España (Sala 1. a) de 10 de marzo de 2001 y de 4 de marzo de 2013.

${ }^{12}$ En este tema es destacable que, por regla general, se produce per se un daño, un perjuicio, una frustración, en su interés material y moral. Gómez (2007), pp. 19-25. Igualmente, ver la Sentencia del Tribunal Supremo de España (Sala 1.a) de 25 de febrero de 2000 y la Sentencia de la Audiencia Provincial de Valencia de 2 de julio de 2010 (Sala 6. ${ }^{a}$ ).
} 
presidir las obligaciones bilaterales; con la facultad que tienen los tribunales de moderar las responsabilidades dimanantes de una obligación (arts. 1.103 y 1.154 del Código Civil), y con el favorecimiento de la subsistencia del vínculo obligatorio por medio del respeto a las obligaciones nacidas válidamente, impidiendo su resolución en los casos en los que no se patentice una voluntad rebelde al cumplimiento, ni exista un hecho obstativo que de un modo absoluto, definitivo e irreformable lo impida ${ }^{13}$.

Por último, el párrafo cuarto del precepto que se examina regula: "Esto se entiende sin perjuicio de los derechos de terceros adquirentes con arreglo a los artículos 1.295 y 1.298 y a las disposiciones de la Ley Hipotecaria". La extinción de la relación sobrevenida en función de la resolución -a la que se refiere el término "esto" - produce sus efectos retroactivamente volviéndose a un estado jurídico preexistente. Lo que trae consigo que tal resultado no sea entendible de modo que deje a beneficio de un contratante las prestaciones que del otro haya recibido. Ello equivaldría a proteger un enriquecimiento injusto.

La irretroactividad se adapta por disposición legal a la mecánica de las acciones rescisorias, que institucionalmente no perjudican a los terceros que hubieran procedido de mala fe, a pesar de que las dos figuras no coincidan y respondan a diferentes exigencias ${ }^{14}$.

\section{Fines y objetivos de las resoluciones judiciales en la aplicación del artículo 1.124 del Código Civil español}

\subsection{Referencia a los derechos implicados}

Lo que se pretende es que la resolución judicial se refiera al amparo y al ejercicio del derecho subjetivo de la parte cumplidora. En el primer punto, ocurre si tenemos en cuenta que en la experiencia de una relación jurídica aparecen dos posiciones, de "poder" y de "deber": la primera, activa y comprensiva de lo que en la relación hay de atribución a un sujeto; la segunda, pasiva y abarcante de la situación de poder proyectada hacia otro sujeto y, si reflexionamos sobre el hecho de que las obligaciones bilaterales revisten la particularidad de que cada parte ostenta las posiciones activa y pasiva ${ }^{15}$.

13 Mosco (1982); VISINTINI (1999). Al respecto ver las Sentencias del Tribunal Supremo de España (Sala 1. ${ }^{\text {a) }}$ de 29 de diciembre de 1995 y 21 de marzo de 2012.

14 TerRÉ et al. (2009), pp. 305 y ss. Ver las Sentencias del Tribunal Supremo de España (Sala 1.a) de 24 de septiembre de 2010, 15 de octubre de 2013 y 3 de diciembre de 2013.

15 Hohfeld (1995), pp. 45 y ss., explicita las relaciones jurídicas que pueden resultar de los derechos subjetivos, siendo innovadora la reelaboración realizada por Ross (2005), pp. 211 y ss. En cuanto a la teoría del "interés jurídicamente protegido", confróntese lHeRING (2011a), pp. 1.025 y ss. Ver, a su vez, sus obras (2008) y (2011b); SAVIGNY (2005). 
Se evidencia que en la mayoría de la jurisprudencia sobre tales casos puede haber un interés jurídicamente protegido, pero no un derecho, siendo lo decisivo para su existencia el que la tutela jurídica del interés sea puesta a disposición de un sujeto. De lo que se deduce que, toda vez que la protección que el legislador asigna a un tipo de interés traduce el establecimiento de una norma jurídica, el derecho subjetivo amparado es la misma norma en cuanto que se pone a disposición del individuo. En síntesis, cuando un sujeto tiene un derecho subjetivo respecto a otro, de algún modo alcanza una posición superior a la de su deudor, porque a la fuerza de su derecho se asocia la necesidad de ser respetado y de que sea pagado lo debido. El hecho de que tal traslado de interés se haya de efectuar simultáneamente nada añade a su reciprocidad y a la integridad de la libertad de cada uno, sólo que el acreedor viene asegurado en el interés que se halla bajo el poder del deudor, equivalente, subjetivamente hablando, a lo que él ha "entregado" ya, o está dispuesto a entregar, bajo una estructura jurídica que vincula la obligación del deudor a tal efecto ${ }^{16}$.

Pero no todo queda en la mera protección del derecho subjetivo del acreedor, éste tiene la posibilidad jurídica de ejercitarlo, actuando su contenido de forma facultativa, no obligatoria, al exigir cualquiera de las consecuencias previstas en el artículo 1.124 del Código Civil a causa del incumplimiento (derecho subjetivo privado), por la puesta en marcha de la reclamación de una decisión particular en el litigio suscitado (derecho subjetivo público relativo a la tutela judicial) ${ }^{17}$.

La idea anterior se conecta con un momento previo patentizado en el equilibrio o indiferencia respecto a los términos afectados por el derecho constituido por una facultad, como doble modalidad para pedir el cumplimiento o la resolución de la obligación (más el resarcimiento de daños y abono de intereses). Una vez que se ha producido la no actividad del deudor, en un cumplimiento que precisa ser a la vez el de la otra parte, el acreedor, en virtud de la facultad aludida, puede utilizar la libertad que tiene en su mano para actualizar la posibilidad inicial de su poder ${ }^{18}$.

El mecanismo de ejercicio del derecho subjetivo tiene la función de obtener el interés que el acreedor no ha satisfecho (en el supuesto del cumplimiento de la obligación incumplida), en unión con el respeto que deben merecer la

16 Gervais (1961), pp. 241 y ss.; IOnescu (1978). Ver, a título de ejemplo, las Sentencias del Tribunal Supremo de España (Sala 1. ${ }^{\text {a) }}$ de 23 de mayo de 2005 y 3 de julio de 2013.

17 Romano (1995). Confróntese también Mazzarese (1996a), (1996b), pp. 201-228. Ver la Sentencia del Tribunal Supremo de España (Sala 1. ${ }^{a}$ ) de 17 de octubre de 2007.

18 Frosini (1960), pp. 1047 y ss. 
ley y los pactos válidamente celebrados. O dejar sin efecto la obligación, lo que es proyección también de un interés contrario, derogatorio del postulado pacta sunt servanda por ser el incumplimiento susceptible de generar la pérdida para la parte cumplidora que ha dado o hecho algo, o se ha obligado a dar o a hacer, a cambio de la prestación no ejecutada (en el supuesto de resolución), produciendo una coactividad hasta el límite que alcance la vigencia actual del derecho, sin poder traspasar las limitaciones originadas por la prohibición de un ejercicio abusivo del mismo y de la buena $\mathrm{fe}^{19}$.

De la delimitación del derecho exigible surge la delimitación del deber del deudor con referencia al valor de la prestación consumada por el acreedor, según los términos reglamentados por la norma jurídica o por el uso de la propia libertad sin invadir el ámbito jurídicamente asignado ${ }^{20}$.

\subsection{Referencia a las prestaciones}

En una primera aproximación, la relación objeto-prestación, y, por tanto, objeto-equivalencia, es obvia. Pero la idea de equivalencia escapa del tratamiento aislado que de cada prestación hace el ordenamiento, tratamiento que se lleva a cabo en la dimensión de la viabilidad de lo que las partes proponen como objeto. Dicha viabilidad es medida por la idoneidad y la aptitud, y suele hacer entender el elemento de la causa en la fase de formación del contrato para proyectar sobre la etapa del cumplimiento la idea de la equivalencia en la efectuación de las obligaciones ${ }^{21}$.

La noción que desentrañamos no es de orden público y, salvo en la realización normativa y en el fraude, es libremente fijada, ya que, por la índole del Derecho privado, la norma civil es la directa y específicamente acordada por los sujetos. En conformidad, la fuente convencional por la que se originan las obligaciones tratadas siempre es onerosa, en ellas cada parte se obliga según una contraprestación que recibe o espera recibir, pretendiendo obtener un provecho o ventaja. El equilibrio del acto jurídico oneroso no sólo está apegado a la valoración económica de las contraprestaciones que invoca la igualdad de las ventajas y sacrificios, sino que también es relativo. Es convencional, según la apreciación de los sujetos en un momento concreto, escudado en la actuación

19 Natol (1975), pp. 119 y ss.

${ }^{20}$ BrezZIA (1968), pp. 30 y ss.; Moreso (2012), pp. 199 y ss. Ver la Sentencia del Tribunal Supremo de España (Sala 1.a) de 17 de octubre de 2007.

21 Aristóteles (2009), V, 4, 1.132b, en cuanto a la noción de justicia conmutativa. Ver además AreChederRA (1978), pp. 348 y ss.; BaRtholomeyczick (1966), pp. 30 y ss.; HaCkL (1977), pp. 1412 y ss.; Maury (1920), pp. 14 y ss., 20 y ss. 
de la autonomía privada, dejando al libre albedrío de los individuos el logro de la equivalencia justa22.

La estructura bilateral de la obligación garantiza una paridad formal, la cual por razón de su positivización no alcanza a tutelar la equivalencia económica material, pero no la excluye. Se puede esbozar en un efecto normal, respetuoso con el hecho de que la protección del equilibrio contractual como principio general aplicado termina por imponerse cuando se ha incumplido la obligación, haciendo necesario averiguar cuál es el que las partes han establecido entre los objetos. Cada uno de los sujetos mira su propia ventaja e intenta aprovecharse de la posición menos favorable del otro. Constituye la tarea del juez, en esta línea, la realización de una communis aestimatio para impedir que alguien salga perjudicado según el precepto de alterum non laedere, materializado cuando se haya dictaminado el cumplimiento en la práctica de los intereses consensuados y, en el supuesto de sentenciarse la resolución, en la extinción de la relación obligatoria tendente como objetivo inmediato a la recuperación de la cosa transmitida, si es que se ha llegado a transmitir ${ }^{23}$.

Este cuadro de actuaciones se completa con lo tocante al resarcimiento de daños y abono de intereses, en el que entra en juego una valoración dirigida a la posibilidad de sustraer el desequilibrio producido por los daños y perjuicios que el incumplimiento del deudor haya podido crear, manteniendo las estimaciones personales del acreedor.

Así, no es exigible un equivalente exacto, con apoyo en el artículo 1.255 del Código Civil español, que regula la autonomía de la voluntad, y derivado de que el precio no ha de ser objetivamente justo, junto con el modo restringido en el que el mismo texto legal concede la rescisión por lesión (art. 1.294). Se impone la fidelidad a lo pactado (pacta sunt servanda) y se legitiman los desequilibrios de valor conforme a lo convenido según el consentimiento de los sujetos intervinientes, salvo cuando se produce la revisión o resolución de los contratos por excesiva onerosidad, sin llegar a imponer su requerimiento fuera del equilibrio inicialmente concertado. Como ocurre en el caso de la cláusula rebus sic stantibus, la teoría de la base del negocio, la imposibilidad sobrevenida, etcétera. ${ }^{24}$

Se juzga que la medida marcada es la matemáticamente justa en cada caso, ya que, ante conductas en apariencia contradictorias, el que quiere recibir lo

22 Álvarez (2009), p. 96; Prada (1968), pp. 257 y ss.; Sánchez-Blanco (1952), pp. 476 y ss.; Schapp (1931), pp. 13 y 14.

${ }^{23}$ Molina (1981); Valpuesta (1989), pp. 316 y ss. Ver las Sentencias del Tribunal Supremo de España (Sala 1. ${ }^{a}$ ) de 19 de diciembre de 1990 y 16 de septiembre de 1991.

${ }^{24}$ Ver Arana (2005). En este tema hay que separar el "justo precio" respecto al "precio lícito" establecido por disposiciones administrativas que fijan topes máximos para los bienes. Ver las Sentencias del Tribunal Supremo de España (Sala 1. a) de 21 de marzo de 2012, 17 y 18 de enero de 2013, y 30 de junio de 2014. 
más posible tropieza con el querer del que desea dar lo menos, en aras de lo cual los dos sujetos adquieren su derecho sin pérdida para ninguno de ellos. Todo lo que se puede hacer es que las prestaciones sean evaluadas con arreglo al equivalente efectivo manteniendo una apreciación subjetiva compatible. Por eso la equivalencia estricta y objetiva está llamada a disolverse en la plenitud de la vinculación recíproca y, frente al planteamiento de la categoría cuántica del esquema negocial, se muestra el valor argumental que aporta el criterio de la "mayor reciprocidad de intereses en caso de duda" (art. 1.289 del Código Civil), indicativo del alcance de la onerosidad. Tal reciprocidad exterioriza una correspondencia mutua ajustada a los intereses de las dos partes. El juzgador sitúa los diversos intereses dentro de una totalidad compuesta por el conjunto de elementos que tienen relevancia jurídica ${ }^{25}$.

\subsection{Referencia a la actividad implicada}

En todas las resoluciones recogidas se esgrime cómo en el principio qui iure suo utitur neminem laedit el brocardo pacta sunt servanda conforma la otra faceta de una misma realidad. Se requiere a cada uno de los sujetos que intervienen una necesaria fidelidad a sus promesas, consecuencia de la exigencia de una actitud honrada, leal, limpia, recta, justa, sincera e íntegra, apoyada en la confianza respectiva de su cumplimiento para dar y recibir cada parte lo que le corresponde. La actitud es individual de calidad personal, valorada como capacidad de libertad y de responsabilidad frente a la contraparte en el seno de la convivencia colectiva debidamente organizada, estimada como comportamiento debido frente a las responsabilidades que provienen de las obligaciones nacidas del pacto concertado ${ }^{26}$.

A su vez, percibimos que tal idea de que los pactos deben ser respetados se aplica por el reconocimiento de la autonomía de la voluntad con ciertos límites, conceptuada como libertad del hombre para crear relaciones jurídicas y regular su contenido, según lo previsto en el artículo 1.255 del Código Civil español, que dice: "Los contratantes pueden establecer los pactos, cláusulas y condiciones que tengan por conveniente, siempre que no sean contrarios a las leyes, a la moral ni al orden público".

En síntesis, la relación de hombre a hombre con fines de satisfacer necesidades y conveniencias tiene fuerza vinculante. La libertad se funda en la libertad misma para conseguir el equilibrio y conciliación de los principios de personalidad y libre autonomía de los contratantes, derivados de la vinculación entre el deudor

25 López (1976), p. 833. Sobre el tema, ver también Andrews (2011), pp. 30 y ss., y las Sentencias del Tribunal Supremo de España (Sala 1. a) de 4 de julio de 2007 y 18 de octubre de 2010.

${ }^{26}$ PICOD (1989). Ver la Sentencia del Tribunal Supremo (Sala 1. ${ }^{a}$ ) de 21 de marzo de 2012. 
y el acreedor según la naturaleza de las obligaciones bilaterales, y, yendo más lejos, se funda en la sociedad en su conjunto -porque es imposible organizarla si se puede querer y hacer lo contrario de lo convenido-, sin herir los derechos de los terceros que han tenido en cuenta una conducta para ajustar a ella la suya ${ }^{27}$.

Ahora bien, si la obligatoriedad de lo pactado posee su razón de ser en la autonomía privada, circunscribirla a estos términos denota una visión incompleta que no hace ostensible el apoyo preciso en la seguridad jurídica. Utilizando esta última vía se podrá conseguir una confianza en que el deudor pagará y en que el Derecho actuará si hiciera falta, exteriorizándose la prolongación de la securitas en el reconocimiento que el ordenamiento hace de los propios intereses y de su aplicación en los ajenos, hasta el punto de que serán previsibles las consecuencias que haya de tener la situación actual de los intereses aceptados y regulados positivamente ${ }^{28}$.

Lo normal es que se llegue a reconocer que hay un deber de fidelidad, y que la falta de una coacción plena para imponer al deudor su observancia no es argumento suficiente para negarle naturaleza jurídica. Esto se confirma, puesto que la posibilidad de que en casos concretos no se cumpla la prestación no trae consigo su irrelevancia; lo que importa es la existencia del deber manifestado en la norma y, más específicamente, en el sentido de que bajo su imperio una persona actúa en interés de otro. Cuando nos encontramos ante obligaciones bilaterales, la materialización del interés ha de ser recíproca según corresponda con las posiciones de acreedor y deudor de cada uno de los intervinientes ${ }^{29}$.

La justificación normativa dentro del Código Civil de España se estructura en un sentido general de la siguiente manera: a) Los contratos son obligatorios y las obligaciones nacidas de los mismos tienen fuerza de ley entre las partes (arts. 1.091 y 1.278); b) su obligatoriedad se deriva de la voluntad de las partes, sancionada y amparada por la ley, nunca del juramento (art. 1.260); c) esta obligatoriedad se hace extensiva a todas las consecuencias que, sin estar expresadas, se deriven de la naturaleza del contrato conforme a la buena fe, al uso y a la ley (art. 1.258), y d) en razón de la obligatoriedad del contrato, no pueden dejarse la validez y el cumplimiento del mismo al arbitrio de uno de los contratantes (art. 1.256) ${ }^{30}$.

\footnotetext{
27 Álvarez (2011), pp. 2025-2078.

28 Confróntese la teoría sostenida por VILLA (1993) y los argumentos de DwORKIN (2002), pp. 257 y ss.; RAWLS (2002), pp. 187 y ss.

${ }^{29}$ Hernández (1988), pp. 29 y ss. Ver, por ejemplo, la Sentencia del Tribunal Supremo (Sala 1. a) de 17 de octubre de 2007.

${ }^{30}$ Lo dicho se adapta al esquema presentado por CASTÁN (2008), pp. 610 y 611; Nieto (2000); Nieto(2005); Valpuesta (1989), pp. 273 y ss.
} 


\section{Problemas planteados y soluciones aportadas basadas en la acción compensatoria}

Sin embargo, las líneas que las resoluciones judiciales han seguido tradicionalmente han planteado ciertos problemas. En lo expuesto hasta ahora se muestra que el equilibrio de las prestaciones dentro de las obligaciones bilaterales queda destruido por el incumplimiento total o parcial, voluntario o involuntario, de alguna de las partes. Dado el incumplimiento, y en los aspectos que no hubieran sido previstos en el contrato, el objeto de igualar tales prestaciones habría de buscarse usando unas soluciones hipotéticamente derivadas del cuadro contractual, en los términos que aquéllas habrían sido definidas y aceptadas bilateralmente. Por eso, el método preferente para resolver los problemas del incumplimiento habría de recurrir a modalidades de responsabilidad dependientes del contrato, más que a normas de culpa civil, que no son capaces de centrarse en las posibilidades y modalidades de resarcimiento como medio de reparar el bien jurídico protegido -los intereses del acreedor-sin experimentar empeoramiento innecesario de la situación del deudor.

Ello hace necesario encontrar una figura jurídica capaz de completar las soluciones contenidas en el artículo 1.124 del Código Civil: el cumplimiento o la resolución de las obligaciones (más el resarcimiento de daños y abono de intereses si procede), con otras no integradas en el precepto. Tal exigencia se adquiere de la contemplación de la realidad conflictual que nace entre los sujetos de obligaciones bilaterales, desde el momento en que se produce su incumplimiento por alguna de las partes y se acude a la Administración de Justicia para que se salde satisfactoriamente la controversia originada. En la mayoría de los supuestos lo que ocurre es que se termina por no responder a los intereses de los titulares de obligaciones bilaterales, causa por la que se comienza el iter recursivo que alarga y encarece los procesos para que, muy frecuentemente, se llegue a la misma conclusión por desestimación ${ }^{31}$.

Así, la superación del problema debe radicar en la propia legislación que habría de elaborar alguna solución distinta de las ya diseñadas y aplicadas, que recogiera el sentido del sistema jurídico dentro del campo tratado. La figura que nosotros ofrecemos tiene su base en la compensación como solución más acorde con la justicia que se intenta obtener en cada uno de los supuestos acaecidos en el arreglo de controversias bilaterales, según los intereses y circunstancias concurrentes, quedando abierta a todo tipo de críticas, mejoras

31 Ver, por ejemplo, las Sentencias del Tribunal Supremo de España (Sala 1. a) de 10 de marzo de 2001, 31 de mayo de 2002, 19 de enero de 2005, 23 de mayo de 2005, 7 de febrero de 2013, 4 de marzo de 2013 y 3 de julio de 2013. 
y nuevas aportaciones. Por lo que a continuación estudiaremos una serie de directrices y finalidades asimiladas en lo posible a la solución compensable.

De acuerdo con su definición, la compensación se efectúa con sencillez y practicidad. Cualquiera de las expresiones empleadas por las sentencias seleccionadas -"pago abreviado" o "forma de pago", "permuta de deudas", "equivalente a pesar o balancear dos obligaciones" o "supresión de dos pagos"- proporciona a cada uno de los acreedores la ventaja de la facilidad para obtener el cumplimiento de las deudas. La argumentación se exterioriza en una doble vertiente: La de la agilización en la solución al incumplimiento de obligaciones, logrando una economía procesal e inherentemente material, y la de la comodidad de las partes en el modo de ejecutarse el pago. El primer punto se demuestra, puesto que si esta figura jurídica tiene la función de extinguir dos obligaciones en la medida en que el importe de una esté comprendido en el de la otra, pesándolas simultáneamente las partes se ahorran la realización de una doble operación que aumentaría y complicaría el proceso y su coste ${ }^{32}$.

Esta doble operación que se suprime satisface los intereses del acreedor A contra el deudor B en una relación jurídica C. Y las del acreedor B (que es deudor de $\mathrm{A}$ en la relación $\mathrm{C}$ ) contra el deudor $\mathrm{A}$ (que es acreedor de $\mathrm{B}$ en la misma relación) en una relación jurídica D. Por consiguiente, lo anterior se reduce a una actuación apoyada muy significativamente en la equidad y el principio de "no contradicción", en la que se considera que, por un lado, siendo A acreedor de B y, por lo tanto, A deudor de B, da el resultado conjunto de una deuda global en la que cada acreedor cobra por medio de su liberación respectiva. En el ejemplo visto, ni A ni B devienen acreedores si las deudas eran idénticas; o bien A o B aparecen como acreedores de B o A respectivamente, según cuál sea la cantidad diferencial y a favor o en contra de quién concurre ${ }^{33}$.

Según dijimos, la compensación también ofrece una comodidad a las partes al pagarse, valiéndose de la evitación del empleo de numerario. En vez de tener que realizarse dos pagos entre las mismas personas, cada acreedor cobra en razón de la liberación de su respectiva deuda, y no tiene que verificarse ninguna entrega efectiva si ambas deudas son de la misma cuantía y entre personas iguales, dándose por saldadas. $\mathrm{O}$, en caso contrario, verificándose el pago de la diferencia por el deudor de la mayor. En definitiva, lo que conlleva la facilidad del cumplimiento de las deudas, valoradas en los extremos tratados, es el evitar pagos repetidos y el transporte de dinero necesario para la entrega, con

32 JIMÉNEZ (1999).

33 Merlin (1991); SChlesinger (1957), pp. 722 y ss. 
el propósito de "no ocasionar daños a nadie", producto de un obrar racional y lógico que acomoda las controversias surgidas y sus conclusiones a una situación lo menos perjudicial y lo más beneficiosa posible ${ }^{34}$.

Esta función consiste en general en la protección, seguridad o defensa frente a un peligro que puede tener muy diversos contenidos y que sirve para reforzar la confianza que cada sujeto tenga en la persona con la que inicia una relación jurídica. El caso visto se configura como un aseguramiento en la efectividad del pago, según el crédito que cada deudor tenga contra la parte contraria por satisfacerse con la prestación que es debida a la contraparte. Aceptando la compensación, los créditos que tenemos contra otros quedan garantizados por las deudas que con respecto a ellos poseemos. Esta combinación es ventajosa para las dos partes, pues cada una tiene más interés en pagar que correr el riesgo de la insolvencia de la otra, evitando que el deudor más diligente corra el riesgo de no cobrar lo que se le debía después de haber satisfecho su deuda a causa de la insolvencia ${ }^{35}$.

La explicación se encuentra en la equidad. El deudor que pagase, y sincrónicamente fuera acreedor en virtud de la otra obligación, se expondría a no poder cobrar su crédito por devenir insolvente con posterioridad el otro deudor, pareciendo más equitativo que ninguno de los deudores haga el pago efectivo con evitación del riesgo de pagar y no cobrar. Este riesgo que se elimina se califica de injusto y desleal con respecto al comportamiento de quien reclama un crédito siendo deudor del demandado. Contrario a la buena fe es pedir lo que luego ha de ser restituido ${ }^{36}$.

Sin embargo, en el supuesto de que haya varios acreedores del deudor, la representación que la compensación viene a tener es la de una especie de privilegios a favor del acreedor que alega su derecho con preferencia a los demás que son burlados ante la habilidad y prontitud de resarcimiento de lo que se adeuda. Por tanto, si en la relación aislada de las personas que son recíprocamente acreedoras y deudoras resulta equitativa la operación compensatoria, cuando se produce la situación de concurrencia de acreedores, el acreedor-deudor se libra de la ley del concurso cobrando íntegramente su crédito mediante la liberación de su deuda, de modo que quedan los restantes acreedores del insolvente. La compensación, como equivalente a un pago efectivo, implicaría un privilegio para el acreedor que se beneficiase de sus

34 Carbonnier (2000), pp. 545 y ss.; Larenz (1959), p. 426.

35 CASTÁN (2008), p. 471.

36 Ver las Sentencia del Tribunal Supremo de España (Sala $1 .{ }^{a}$ ) de 14 de marzo de 2004 y 7 de diciembre de 2007. 
efectos, por lo que no cabe admitir preferencia alguna fuera de los privilegios establecidos en la ley ${ }^{37}$.

Del tratamiento dado a la garantía se deduce que su objeto es una preservación para la salvaguarda de la seguridad y certeza jurídicas del derecho que tiene cada sujeto a colmar sus propios intereses, sin que se le impongan mayores cargas que beneficios. A. Pérez decía textualmente en el siglo XVII: "La obligación de justicia, en cuanto sea de justicia, nunca impone cargas superiores a los beneficios. Ya sea a causa de que responde a una obligación igual por el acreedor, ya porque tiene el objetivo de compensar las cargas de la obligación". Se entiende como derecho subjetivo en la dimensión de su amparo y de su ejercicio, en el sentido expresado en las sentencias que dictan el cumplimiento o la resolución de las obligaciones bilaterales a las que nos remitimos, modificándose el ámbito en el que nacen y se desenvuelven los derechos de las partes cumplidoras frente a las incumplidoras. En el supuesto estudiado en el epígrafe anterior actúa un deudor que ha incumplido la obligación, mientras que el otro sujeto ejerce como acreedor habiendo ya cumplido o estado dispuesto a hacerlo. Por el contrario, en la compensación las dos partes de una relación jurídica son deudoras la una de la otra, aunque tal deuda haya tenido un origen diferente, surgiendo de una relación jurídica que no se corresponde idénticamente ${ }^{38}$.

En consecuencia, se ha de pretender la reparación del perjuicio que opera en el desequilibrio nacido del incumplimiento mediante el ajustamiento de los intereses de las partes, valorándose los perjuicios producidos al acreedor por el incumplimiento; al deudor en caso de realizarse el cumplimiento; a los terceros no intervinientes en la relación jurídica de la que nace la obligación bilateral, en los casos de cumplimiento y de incumplimiento, y a la sociedad en los mismos supuestos, con el fin de llegar a una decisión satisfactoria para todos en la que cada uno se resarza debidamente, de acuerdo con el modelo equilibrador de las prestaciones que haya sido fijado ${ }^{39}$.

Por otro lado, se constituye la imposición de sanción unida a la corrección, en tanto se sacrifican los intereses ilegítimos que quiere satisfacer el deudor incumplidor por medio del incumplimiento, o los pertenecientes al acreedorcumplidor que representan un abuso de derecho en el supuesto de cumplimiento.

\footnotetext{
37 Espín afirma que la posterior declaración de suspensión de pagos no paraliza la compensación ya hecha, y que se ha de descartar la compensación cuando uno de los interesados cae en concurso de acreedores o quiebra, EsPín (1983), pp. 160 y 161.

38 Pérez (1661), disp. II, cap. 3, n. 79. Confróntese Álvarez (1979), pp. 87 y ss.; Cordón (2009); García et al. (2010); Gaspar (1998); MunNé (2004); Pérez-Cruz (2011).

39 Davis (1980); Rebuffa (1993). Ver también sobre el tema Burrows (1993); Rentería (2002).
} 
No hablamos de sanción cuando se sacrifiquen ciertos intereses legítimos en virtud de la acción compatibilizadora, expresión del principio lógico de "no contradicción" que corresponde a la satisfacción de otros intereses legítimos, no importando que sean contrarios por su procedencia.

\subsection{Referencia a los derechos implicados}

Tal fundamento se conecta con la función de garantía desempeñada por la compensación. En las mismas sentencias en las que se aplica dicho criterio se defiende el amparo y ejercicio de un derecho subjetivo comprendido en sus dimensiones privada y pública. Esto se comprueba en tres diferentes modalidades opcionales otorgadas al demandado y concatenadas a la utilidad y conveniencia que se quieren hacer valer, referidas a: a) alegar que la deuda que se le reclama ha sido extinguida por compensación desde el momento en que concurrieron; b) contestar el crédito reclamado en juicio y alegar subsidiariamente su crédito compensable. Lo que significa solicitar que, para el supuesto de que el juez pretenda hacer subsistir el crédito del demandante, atienda la petición subsidiaria eventual, y c) no oponer su crédito compensable a la reclamación actora (que es válida y eficaz, si no se le opone la compensación del demandado) y reservar su crédito para reclamarlo de forma independiente ${ }^{40}$.

Esta triple facultad puede ejercitarse como contraderecho, al ser una excepción propia, si el acreedor de un deudor le demanda en juicio para el pago de una deuda. Su sustanciación reside en que la oposición se funda en un contraderecho suyo, el crédito compensable que tiene vida autónoma y que puede hacerlo valer en ese proceso en el que se le reclama el pago de una deuda contra el actor (por vía de excepción o reconvención) o en un proceso independiente (por vía de acción), al tratarse de una excepción impropia ${ }^{41}$. El juez, ponderando los hechos probados y la totalidad de los intereses afectados, habrá de limitar jurídicamente el derecho de crédito, limitación apoyada en la naturaleza de la obligación bilateral con el sentido expresado. En congruen-

\footnotetext{
40 TAPIA considera que "la compensación propia tiene una fundamentación que nada tiene que ver con la equidad. Quien ostenta un crédito-autónomo-compensable sopesa su conveniencia o no de oponerlo en compensación. El fundamento de la compensación no reside en razones distintas de la utilidad o conveniencia del titular del contracrédito" (1988, pp. 103 y ss., y 152). Sentencias del Tribunal Supremo de España (Sala 1. a) de 31 de mayo de 1995 y 30 de abril de 2008.

${ }^{41}$ TAPIA (1988), p. 77. La mayoría de las veces, la naturaleza procesal de la compensación ha sido hecha valer por el Tribunal Supremo como una reconvención. En muy pocas ocasiones se han considerado como excepción propia, apoyando dicha postura sobre todo la doctrina procesalista y los autores del Derecho histórico. Y, por último, ha sido inscrita como defensa, directa o indirectamente, por la doctrina civilista.
} 
cia, el demandante no tiene más remedio que ver coartada una pretensión no limitada en el contenido del derecho que le compete ${ }^{42}$.

En cuanto a lo que respecta a la valoración de los intereses, se debe dar una solución que, dirigida por el sentido de la obligación bilateral y de la normativa global, abarca completamente los intereses que de alguna manera juegan conforme a las pautas dichas. La valoración en sí exige una toma de posición respecto a los intereses que impone una actividad decisoria. Se diferencian la percepción de los mismos, preferentemente receptiva y pasiva, de la ponderación, sustancialmente activa, centrándose en el sentido primario del juicio en que al interés enjuiciado corresponde el predicado expresado en él ${ }^{43}$.

La verdadera dificultad del enjuiciamiento reside en que los intereses no vienen dados de la manera inmediata en la que lo hacen los objetos de percepción. El juzgador no adquiere consciencia de ellos más que en actos de toma de posición valorativa frente a acciones o acontecimientos concretos, su característica es la atipicidad e inconstancia, la heterogeneidad y desuniformidad, siendo estimados plenamente. En otro caso, no se daría más que una solución parcial desconocedora de la realidad que no sopesara unos intereses con otros ${ }^{44}$.

La acción judicial dirige la valoración de los intereses a la consecución del equilibrio de las prestaciones observado en el funcionamiento correctivo, estableciéndose ciertos límites que cercan la libertad del arbitrio judicial, ya que la inteligencia valorativa de lo "justo" se ha de encuadrar dentro del alcance marcado por el Derecho vigente. Lo que se analiza es la "mediedad", la alteridad, su conexión con la decisión individual y, en general, las magnitudes y cualidades que van tomando los requisitos, el contenido y los efectos jurídicos; viendo cómo funcionan para lograr una adecuación y conjunción compatible de los intereses contradictorios con relevancia jurídica. Por definición se trata de un conjunto mediador del objeto al que se refiere la relación obligatoria bilateral por la que conocemos los sujetos que pueden estar obligados, constituyendo la actividad en la que todos los titulares de derechos subjetivos influyen y los de los deberes son influidos ${ }^{45}$.

Las condiciones necesarias para la aplicación de la compatibilización cuando se incumple una obligación bilateral son: a) una relación entre iguales, en la que cada una de las partes tiene una naturaleza igualmente constituida por el doble aspecto de acreedor y deudor. A pesar de que la parte incumplidora es

42 Confróntese Stone (1968), pp. 341 y ss. y, particularmente, Giuliani et al. (1996).

43 Heck (1999), pp. 60 y ss.; Müller-Erzbach (1932).

44 De acuerdo con el mismo concepto de "interés" contenido en BetTI (1957), pp. 838 y ss.; RümeLIN (1930); Stoll (1931). Ver también Larenz (2010), pp. 229 y ss.

45 CAstañeda (1986-1987), pp. 71 y ss. 
únicamente deudora frente a la contraria que es acreedora, sin una comprensión de disparidad de trato. Igualmente han de considerarse sin ningún privilegio los sujetos que no se constituyen en partes del vínculo obligatorio, pero que ven afectados sus intereses; y b) una identidad del valor de las prestaciones como apoyo del intercambio, que, de acuerdo con lo ya expuesto, sea la que subjetivamente se haya querido establecer como señal de correspondencia.

Producida de hecho una interferencia entre intencionalidades por el incumplimiento, la resolución judicial se reconduce a obtener la coexistencia como criterio normativo de la denominada justicia general, por medio de la "no exclusión" de nadie. De otro lado, colabora para asegurar objetivos intencionales comunes dentro de las condiciones admitidas, valorando la "participación" como criterio normativo de toda organización en la que se ejerza una administración de justicia. Y, finalmente, enlaza la "libertad" de cada uno para consagrar sus propias finalidades, sin menoscabo de las oportunidades que para análogos objetivos atañen a los demás ${ }^{46}$.

\subsection{Referencia a las prestaciones}

La reciprocidad de las obligaciones no es un requisito para que sea dictado el cumplimiento o la resolución, sino el presupuesto necesario para el ejercicio de la opción encuadrada en el artículo 1.124 del Código Civil, que justifica la atribución de tales facultades al perjudicado. Se necesita una acusada reciprocidad de manera que no se conciban unas obligaciones sin las otras, al darse de obligación a obligación y de derecho a derecho ${ }^{47}$.

Pero ¿cuál es el sentido que tiene lo dicho?, ¿cuál es su contenido? No hay duda de que mayoritariamente la doctrina y la jurisprudencia sostienen una postura clásica, centrada en la creencia de que las obligaciones nacidas entre los sujetos funcionan a tenor de varios intereses que se entrecruzan de todas las formas posibles: sumándose, restándose, acrecentando su efecto singular, disminuyéndolo, destruyéndolo..., recíprocamente. Aparece una heterogénea pluralidad que se mueve en la realidad social, y que parte de la interdependencia que existe entre ellos para llegar a la fundamentación de la armonía producida por el cumplimiento voluntario, comportándose los sujetos de acuerdo al precepto de honeste vivere, de modo fiel y leal a lo pactado según la confianza que en ellos se tiene, o que se fija en el conflicto originado por el incumplimiento derivado de una conducta desleal.

46 En este sentido, ver KRAJEWSKI (1977); STEGMüLler (1976).

47 Andrews (2011), pp. 40 y ss. Ver la Sentencia del Tribunal Supremo de España (Sala 1. ${ }^{a}$ ) de 17 de octubre de 2007. 
Se da una unión tan indisoluble que cada prestación no puede pervivir sin la opuesta, formando cada una la mitad de la única relación jurídica, donde cada sujeto se obliga con el fin de obtener el cumplimiento que cristaliza en el objeto perseguido. Cada obligación tiene su causa en la otra prolongada más allá del momento formativo que las generó, es decir, en la relación de cambio efectivo entre las prestaciones correspondientes que proceden del mismo título ${ }^{48}$.

De aquí la explicación de que, si una parte no cumple, la de la contraparte deviene sin causa y el contrato del que derivan las obligaciones bilaterales no puede ser regularmente concluido. El carácter estático de la bilateralidad se supone como un obligarse en función de algo, dirigido a una finalidad. No basta recabar el porqué comprometerse, es preciso ir más allá e inquirir ¿para qué obligarse a título de contrapartida? El predominio de la causa en la bilateralidad-fin hace que se coloque en la reciprocidad de prestaciones emanada de la onerosidad del contrato del cual nacen, buscando las partes una mutua equivalencia o ventaja dentro de un equilibrio en función del interés que satisfacen las prestaciones. Se señala que la onerosidad procede necesariamente de un acuerdo en cuyo fondo establece entre las relaciones recíprocas un nexo teleológico o vínculo de fin, de forma que cada una de las prestaciones es querida como condición para que la parte contraria quiera la prestación recíproca. Brevemente, se requiere que una de las atribuciones se quiera como contravalor de la otra ${ }^{49}$.

En definitiva, según el criterio expuesto, el juzgador suele superar el mero concepto de "correlatividad" y falla que el deudor ha de cumplir con su obligación para producir una reposición causal, conforme con la idea de rehacer el curso de las causas para que no se pierda la garantía constitutiva de la relación jurídica fuente de las obligaciones o, lo que es lo mismo, para que se consiga el estado final previsto queriendo asentar la res integra en la dirección de su consumación.

El proceder a la resolución se debe a que la causa de la obligación sea la prestación y no la obligación de prestar. Es obvio que, en caso de sobrevenir un incumplimiento, no hay prestación y no hay causa; lo que se quiere evitar es que el acreedor se halle obligado sin causa al no cumplir el deudor ${ }^{50}$.

Por otro lado, la reciprocidad entre acreedores y deudores es una de las condiciones necesarias para que pueda haber compensación, de acuerdo con

48 Ogayar y Ayllón (1983), pp. 72 y 73. Sobre el tema, ver Bellelli (1992), Salanié (1998) y la sentencia indicada en la nota anterior.

49 AndREWs (2011), pp. 50 y ss.

50 Seriaux (1985), p. 77. Ver como ejemplo las Sentencias del Tribunal Supremo de España (Sala 1. ${ }^{a}$ ) de 4 de enero de 1992, 17 de marzo de 1995, 13 de julio de 2005 y 10 de octubre de 2005. 
el artículo 1.195 del Código Civil español, junto a la necesidad de serlo por derecho propio (id.) y principalmente (art. 1.196.1 de id.). Con la utilización de este criterio se reducen todos los aspectos señalados a la pura reciprocidad, lo que se demuestra porque en realidad no es deudor o acreedor la persona que es representante de quien inexactamente se podría decir que es deudor o acreedor por derecho de otro (del representado, verdadero titular de la deuda o del crédito). En cuanto a la índole de la principalidad, se exige que se excluya el caso de la fianza, manteniéndose superfluamente que el fiador es deudor subsidiario, ya que se aísla por falta de reciprocidad. Finalmente, hay que señalar que cuando haya transición de deuda y el nuevo deudor sea acreedor del acreedor, se produce la compensación, puesto que subsiste el elemento anterior ${ }^{51}$.

Mas lo que interesa es el tema que se aborda como primordial: el de las deudas recíprocas en relación a si han de proceder o no de una misma relación jurídica, si han de ser las deudas independientes, o si es suficiente la interdependencia de las dos atribuciones patrimoniales. Pues bien, algunas veces se dictamina que no importa la fuente de la que las obligaciones procedan, en contraposición a la tendencia más común de requerir que los créditos tengan distinto origen y consten en diferentes títulos, no identificándose las causas por las que resulten recíprocamente acreedora y deudora una parte de la otra ${ }^{52}$.

Se dejan fuera del concepto las obligaciones bilaterales que se derivan de una relación jurídica unitaria, en las que su dualidad se resuelve en mutua condicionalidad, funcionando las obligaciones asumidas por cada parte como causa de las aceptadas por la otra en régimen de voluntaria y esencial equivalencia. La bilateralidad así articulada aparece ajena a la situación que propicia la compensación propia en el sentido originario y finalista, cosa que no impide que se dé esta organización cuando las obligaciones tengan una fuente diferente y cumplan con los cánones expuestos. Por lo que cuando existe una relación bilateral su enjuiciamiento debe ser simultáneo, sin posibilidad de remitir a un juicio posterior las obligaciones de uno de los sujetos que son parte ${ }^{53}$.

\subsection{Referencia a la actividad}

El planteamiento se apoya en la vieja idea de la "justicia correctiva", que conduce a diseñar un marco de solución sistemática consistente en un modelo denominado "compensación correctiva". Tal solución posible tendría un

\footnotetext{
51 Albaladejo (1980), pp. 312 y ss.; Atiyah (1990), pp. 93 y ss.

52 Terré et al. (2009), p. 44. Ver las Sentencias del Tribunal Supremo de España (Sala 1.a) de 18 de marzo de 1998, 7 de octubre de 2005, 5 de junio de 2007 y 1 de octubre de 2010.

53 Castán señala que la bilateralidad supone una relación y la compensación dos relaciones obligatorias, postura con la que coinciden la mayoría de los autores. CASTÁn (2008), pp. 475 y ss.
} 
fundamento de naturaleza discrecional y equitativa muy sólido, que se traduce por escuelas dispares con postulados contrapuestos, y estaría en correlación con los Principios del Derecho Europeo de Contratos y con la Propuesta para la Modernización del Derecho de Obligaciones y Contratos ${ }^{54}$.

En el Derecho positivo comparado, el ejemplo más adecuado al planteamiento en que nos movemos se inscribe en el Código de Procedimiento Civil italiano de 28 de octubre de 1949, que preceptúa en el artículo 114: "El juez ya sea en primera instancia, ya en apelación puede fallar con arreglo a equidad si ambos de común acuerdo lo solicitan del juzgador". La Exposición de Motivos de la ley aclara la causa de tal regulación al decir que, en ambos casos, el interés y la importancia concedida a la conciliación y a la decisión de equidad significan el firme propósito de eliminar pleitos estériles y de acomodar la litis al tratamiento que por suposiciones de la realidad exige la cuestión litigiosa. Se argumenta que si era razonable atribuir a los litigantes la facultad de pedir a unos árbitros de su elección una solución equitativa de la controversia, por paridad de razón habría de reconocérseles la de dirigirse con la misma confianza al juez profesional, remitiéndose al sentimiento de equidad por él adquirido en el ejercicio de su ministerio. Tal regulación ha de completarse con la modificación llevada a cabo por el artículo $3^{\circ}$ de la ley de 30 de julio de 1.984, referente al artículo 113 in fine de aquel Código, que sostiene que "el conciliador decidirá según equidad observando el principio regulativo de la materia" ${ }^{\prime \prime 5}$.

La equidad constituye el medio técnico de actuación compensatoria, a pesar de que nunca podemos mantener que se fundamente sólo en ella. En base al esquema trazado por Chiodi, articulado en cuatro principios: a) la justicia es un valor tendencial del juicio normativo práctico; b) la equidad es una justicia práctica y concretizada; c) por esto se puede decir que la justicia práctica es el valor tendencial del Derecho, y d) la ley es la forma de realización práctica y concreta del Derecho; en conjunto se mantiene una concepción de la igualdad como justicia en su actuación discrecional, recogiendo la idea presentada en las decisiones que dictan las formulaciones ya estudiadas. Mas su grado de aplicación es superior por intensidad y extensión si la comparamos con ellas ${ }^{56}$.

En este caso apreciamos que, al ser mayor el grado de discrecionalidad dejado al juzgador, el de la equidad también lo es, habiéndose de adecuar el juzgador a la necesidad del restablecimiento del equilibrio de las prestaciones

54 Clemente (2011); Díez-Picazo et al. (2002); San Miguel (2011a), (2011b).

55 Desde nuestro punto de vista, para abordar el estudio descrito resultan especialmente valiosos los filósofos del Derecho anglosajones, que hablan de nuevas aplicaciones de la equidad. Ver HanburY y Maudsley (2012), pp. 44 y 45. Ver además Avilés (2006).

56 CHIOdI (1989), p. 112; Quintana (2001). 
a modo de expresión del equilibrio de los intereses. Simultáneamente se dictamina por la corrección operada una decisión mucho más equitativa que tiene en cuenta todos los intereses afectados, no limitativamente los de alguna de las partes, que en ocasiones pudieran dar lugar a un abuso del derecho dañando y sacrificando los de los demás, también legítimos ${ }^{57}$. La noción vista se configura en la línea de que la equidad efectúa el principio de racionalidad perteneciente a la igualdad material o económica (equivalencia de las prestaciones) y formal (relativa al amparo y ejercicio de los derechos subjetivos y a la función social del Derecho).

En el contrato las partes consienten en obligarse respecto de otra u otras. Su elemento más esencial es el consentimiento, definible como "el encuentro de dos declaraciones de voluntad, que partiendo de sujetos diversos se dirigen a un fin común y se unen". Y, en particular, conforme al artículo 1.262 del Código Civil español, es posible sistematizarlo como "el concurso de la oferta y de la aceptación sobre la cosa y la causa que han de formar el contrato". Por lo tanto, en tales declaraciones de voluntad lo que se hace es compatibilizar los intereses de las partes, cada una tiene necesidades y finalidades que miran hacia su mayor satisfacción con un mínimo sacrificio, y llegan a un acuerdo resultante entre ellos en el que habrá de consistir el contenido obligacional a cumplir ${ }^{58}$.

Pero la autonomía privada en el ámbito del contrato no es absoluta y sin cortapisas. En su incesante evolución, los ordenamientos modernos han destacado la llamada "función social" del Derecho, que lo fuerza a entrar en el campo de la autonomía de la voluntad. Es correcto afirmar que el contrato pertenece de una manera dominante, aunque no exclusiva, a la esfera del Derecho voluntario. Decimos que no única porque también el ius cogens despliega su influencia sobre la contratación, limitando la potencialidad creadora de las partes; y, de hecho, el Estado, definidor principal del Derecho positivo, puede establecer las normas generales de la contratación que la limitan para reforzar la justicia y la buena $\mathrm{fe}^{59}$.

Consiguientemente a la necesaria compatibilización de los intereses de las partes actuantes que usan su autonomía de la voluntad, hay que añadir, en concordancia con la existencia de los límites de actuación, que ellos, en el marco del Derecho necesario, se cuidan de garantizar los intereses de los terceros y de la sociedad, pues, bajo la apariencia de símbolos y conceptos ciertamente ambiguos, residen situaciones y relaciones dignas de protección

57 CHIODI (1989), pp. 51 y ss., y los postulados del pensamiento rawlsiano expresados en RawLS (2002a), pp. 237 y ss., y Rawls (2002b), pp. 103 y ss.

58 IRTI (1973), pp. 88 y 89.

59 Ghestin (1980), pp. 144 y ss.; Kerchove y Ost (1997), pp. 126 y ss.; Trebilcock (1997), pp. 25 y ss. 
y aseguramiento ${ }^{60}$. La condición es que se determine una superposición del protagonismo activo, que antes de producirse la infracción por el incumplidor tenían las partes del contrato del que nació la obligación bilateral en cuestión. El juzgador lleva a cabo un cálculo comparativo entre aquellos intereses que se han de satisfacer con su correspondiente grado de sacrificio para adaptar unos con otros. Por ello, la particularización del acoplamiento compatibilizador depende de la actividad judicial que desempeña su función dirimente, fijándose definitivamente en el fallo y no en el contrato ${ }^{61}$.

Para superar los problemas que se suelen producir, se propone otra sustitución en el logro de la misma finalidad que merece ser destacada. Es la relativa al medio que guía las actividades expuestas, en las que en el primer caso los contratantes establecen la obligación de acuerdo con la subjetividad que les mueve en miras cada uno de su provecho, quedando la normatividad del ius cogens en un segundo plano con la calificación de mera cortapisa. Por el contrario, en la compensación que proponemos el juez lo que tendrá en cuenta primeramente será el sentido y alcance de la obligación bilateral y del ordenamiento positivo en su conjunto; y, cuando lo haya obtenido, lo aplicará en relación con los intereses en juego y su modo de satisfacerlos según la solución que nos ocupa.

No obstante, de la imparcialidad del ordenamiento respecto de lo pactado deriva que las garantías de la exigencia del equilibrio de las prestaciones tiendan a un equilibrio que, si es patrimonialmente nivelador, no impida que el riesgo tenga consecuencias contrarias al mantenimiento de una equivalencia material de tipo económico. Tan "normales" son los resultados equilibradores como los que, consecuencia del aleas normal del contrato, redundan en un desequilibrio dentro de una equivalencia subjetiva luego desbordada. Este sentido de "congruencia" impulsa la inteligencia de una legalidad convertida en mediación. Por esta razón es por la que las resoluciones judiciales deben corregir compensatoriamente y pueden modificar los términos expresados en el convenio, orientándose hacia la obtención del máximo equilibrio entre los intereses, si es que sobrevenidamente surgió algún evento que pudiera producir un perjuicio desproporcionado para el deudor, aun en el caso de cumplimiento ${ }^{62}$.

\section{Reflexión final}

En este trabajo se ha pretendido mostrar que debemos plantear nuevos tipos de soluciones judiciales que sirvan para dirimir las controversias surgidas

60 Ver, en general, las obras de Carlier (1992); Lenoble (1990); Pallín (2010). Ver además Lifante (2002), pp. 413 y ss.; LIFANTE (2006), pp. 107-132.

61 Duboc (1989); ENGISCH (2004).

62 Atiyah (1990), pp. 224 y ss.; Elster (1995); Spy (2009), pp. 291 y ss. 
dentro de esa esfera respetando los principios rectores y objetivos propios de los contratos. A estos efectos, es conveniente justificar y aclarar brevemente la potenciación de la solución compensatoria. Tal justificación y explicación centra su atención en la finalidad de su operatividad, en consonancia con el término de la clase de justicia perteneciente a la función judicial. Se ha de intentar, por tanto, conformar una o varias vías de solución actuadas por medio de jueces profesionales que actúen arbitralmente en el ámbito de los conflictos planteados por incumplimiento de obligaciones bilaterales, capaces de satisfacer los intereses legítimos con relevancia jurídica que hayan sido afectados, enraizándose en el sentido de las obligaciones sinalagmáticas y de sus normas reguladoras, que tiene como fin esencial la corrección permitida y no contradictoria con el sistema jurídico ${ }^{63}$.

En síntesis, los elementos que se desprenden de lo dicho son: Primero, en lo que se refiere a los sujetos actuantes, los jueces se convierten en auténticos árbitros ${ }^{64}$. Segundo, por lo que respecta al objeto a tener en cuenta, él es el de las obligaciones bilaterales que tienen un concepto, contenido y estructura ya conocidos, sin que sea necesario ningún requisito complementario. Su funcionamiento se producirá en todos los supuestos en los que haya un incumplimiento de cualquiera de las partes y, por tal causa, se entable un litigio. Tercero, en cuanto a la actividad ejercitada, se ponderan conjuntamente dos obligaciones de la clase citada pertenecientes a sujetos distintos. Su desenvolvimiento es sustentado en la estimación del sentido de la obligación bilateral y de su normatividad de acuerdo con la equidad, superando el juzgador las valoraciones arbitrarias relativas y absolutas. Y, cuarto, la finalidad hacia la que se dirige capitalmente esta compensación es la de lograr una corrección del estado de desequilibrio intolerable, nacido del incumplimiento, que produce ciertos perjuicios más o menos graves a la(s) parte(s), a otros sujetos ajenos al vínculo obligatorio y a la sociedad en su caso, de forma que se satisfagan todos los intereses repercutidos no habiéndose de desproteger ningún interés legítimo con relevancia jurídica, derecho o expectativa, mediante una pretensión en el ejercicio legítimo de la libertad.

\section{BIBLIOGRAFÍA CITADA}

Albaladejo, Manuel (1980): Derecho Civil (Barcelona, Bosch), tomo II, vol. 1. Alonso Pérez, Mariano (1967): Sobre la esencia del contrato bilateral (Salamanca, Universidad de Salamanca).

${ }^{63}$ Aristóteles (2009), V, 4, 1.132 a y 1.332 b.; Ruiz (2011), pp. 187-208.

${ }^{64}$ JaRrosson (1987), pp. 368 y ss. Sobre los límites de la acción del juez, ver IBÁÑEz (2006), pp. 149-169; REDONDO et al. (2009). 
Álvarez Robles, Antonio (2011): "La seguridad en los negocios jurídicos", en: AA.VV., Estudios jurídicos del Colegio Notarial de Barcelona, vol. 2 (Madrid, Marcial Pons), pp. 2025-2078.

Álvarez Vigaray, Rafael (2009): La resolución de los contratos bilaterales por incumplimiento (Granada, Comares).

Andrés Ibáñez, Perfecto (2006): "El juez", en: Díez-Picazo, Luis M. (Coordinador), El oficio del jurista (Madrid, Siglo XXI).

Andrews, Neil (2011): Contract Law (Cambridge, Reino Unido, Cambridge University Press).

Arana, Juan (2005): Los filósofos y la libertad. Necesidad y autonomía de la libertad (Madrid, Síntesis).

ARECHEDERRA, Luis Ignacio (1978): La equivalencia de las prestaciones en el ámbito contractual (Madrid, Montecorvo).

Aristóteles (2009): Ética a Nicómaco (Traducc. María Araujo y Julián Marías, Madrid, Centro de Estudios Políticos y Constitucionales).

AtiYah, Patrick S. (1990): Essays on Contract (Oxford, Clarendon Press). (2005): The Sale of Goods (Londres, Pearson-Longman).

Avilés, Javier (2006): Los contratos de compraventa de bienes de consumo: problemas, propuestas y perspectivas de la venta y garantías en la Directiva 199/44/CE y la ley No 23/2003 (Granada, Comares).

BARTHOLOMEYCZIK, Horst (1966): "Äquivalenzprinzip. Woltenleichkeit und Gegengwichts Prinzipien der modernen Rechtsentwicklung", en: Archiv für die Civilistische Praxis ( $\left.\mathrm{N}^{0} 166\right)$, pp. 30-67.

Bellellı, Alessandra (1992): Il principio di conformità tra proposta e accettazione (Padua, Cedam).

Bettı, Emilio (1957): voz "Interesse (teoría generale)", en: Novissimo Digesto Italiano (Turín, UTET), tomo. VIII, pp. 838-842.

BREZZIA, Umberto (1968): Diligenza e buona fede nell'attuazione del rapporto obligatorio (Milán, Giuffrè).

Burrows, Andrew S. (1993): The Law of Restitution (Londres, Butterworths).

CARbonnier, Jean (2000): Droit civil (París, Presses Universitaires de France), tomo IV.

CARLIER, Jean-Yves (1992): Autonomie de la volonté et statut personnel (Bruselas, Bruylant).

CAstán, José (2008): Derecho Civil español, común y foral (Madrid, Reus), tomo III. 
CAstañedA, Héctor-Neri (1986-1987): "Practical Reason for Doing and Intentional Action", en: Theoria ( $\left.N^{\circ} 4\right)$, pp. 69-96.

ChabAs, François (1966): "Réflexion sur la compensation judiciaire", en: Juris Classeur Périodique (T. I), C. 2.026.

ChIODI, Giulio M. (1989): Equità. La categoría regolativa del diritto (Nápoles, Guida Edit.).

Clemente, Mario Enrique (2011): "La resolución por incumplimiento en la Propuesta para la Modernización del Derecho de Obligaciones y Contratos (2009) de la Sección de Derecho Civil de la Comisión General de Codificación española", en: Boletín del Ministerio de Justicia ( $N^{\circ} 2131$ ).

CoING, Helmut (1951): "Il concetto dell'obbligazione e la disfunzione tra debito e responsabilità", en: Nuova Rivista di Diritto Commerciale, Diritto dell'Economia, Diritto sociale (T. IV), pp. 22-35.

(1996): Derecho privado europeo (Traducc. Antonio Pérez Martín, Madrid, Fundación Cultural de Notariado), vol. 1.

Colin, Ambrosio y Capitant, Henri (1960): Curso elemental de Derecho Civil (Traducc. Redacción de la Revista General de Legislación y Jurisprudencia, Barcelona, Bosch), tomo III.

CORDÓN, Faustino (2009): El arbitraje en España: Ventajas y desventajas (Madrid, Difusión Jurídica).

CRISTÓBAL, Ángel (1989): El incumplimiento de las obligaciones (Madrid, Tecnos).

Davis, Kenneth C. (1980): Discretionary Justice (Conneticut, Greenwood Press Publishers).

Díaz PaIRó, Antonio (1948): Teoría general de las obligaciones (La Habana, Librería Temis).

Díez-Pıcazo, Luis (2005): Los incumplimientos resolutorios (Navarra, Thomson-Civitas).

Díez-Picazo, Luis y Gullón, Antonio (2012): Sistema de Derecho Civil (Madrid, Tecnos), vol. II.

Dífz-PICAzo, Luis et al. (2002), Los principios del Derecho europeo de contratos (Madrid, Civitas).

DuALDE, Joaquín (1949): Concepto de la causa de los contratos (Barcelona, Bosch). Duвoc, Guy (1989): La compensation et les droits des tiers (París, Librairie Générale de Droit et Jurisprudence).

Dworkin, Ronald (2002): Los derechos en serio (Traducc. Marta Guastavino, Barcelona, Ariel). 
ELSTER, JOn (1995): Juicios salomónicos. Las limitaciones de la racionalidad como principio de la decisión (Traducc. Carlos Gardini, Barcelona, Gedisa).

ENGISCH, Karl (2004): La idea de concreción en el Derecho y en la ciencia jurídica actuales (Traducc. Juan José Gil Cremades, Granada, Comares).

Espín, Diego (1983): Manual de Derecho Civil español (Madrid, Revista de Derecho Privado), vol. III.

ESPINAR, Francisco (1969): "Resolución e indemnización en las obligaciones recíprocas", en: AA.VV., Estudios de Derecho Civil en honor del Prof. Castán Tobeñas (Pamplona, Universidad de Navarra), pp. 111-164.

FrosinI, Vittorio (1960): voz "Diritto soggettivo", en: Novissimo Digesto Italiano (vol. V) (Turín, UTET), pp. 1047-1050.

García Villaluenga, Leticia et al. (Directores) (2010): Mediación, arbitraje y resolución extrajudicial de conflictos en el siglo XXI (Madrid, Reus).

GASPAR, Silvia (1998): El ámbito de aplicación del arbitraje (Navarra, Thomson-Aranzadi),

Gervals, André (1961): "Quelques réflexions à propos de la distinction des 'droits' et des 'intérêts'", en: Mélanges à I'honneur de P. Roubier, t. I. (París, Dalloz et Sirey), pp. 241-252.

Ghestin, Jacques (1980): Traité de Droit civil (París, Librairie Générale de Droit et Jurisprudence), tomo II, vol. 1.

GIORGIANNI, Michele (1958): La obligación (la parte general de las obligaciones) (Traducc. Evelio Verdera y Tuells, Barcelona, Bosch).

Giuliani, Alessandro; Ferrantı, lone, y Palazzo, Antonio (1996): L'interpretazione delle norme civile (Turín, Giappichelli).

Gómez Pomar, Fernando (2007): "El incumplimiento contractual en Derecho español", en: InDret, Revista para el análisis jurídico ( $\mathrm{N}^{\circ} 3$ ).

González González, Aurora (1987): La resolución como efecto del incumplimiento en las obligaciones bilaterales (Barcelona, Bosch).

HACKL, Karl (1977): "Áequivalenzstörung und Sittenwidrigkeit", en: Der BetriebsBerater ( $\left.\mathrm{N}^{\circ} 29\right)$, pp. 1412-1415.

Hanbury, Harold Greville y Maudsley, Ronald Harling (2012): Modern Equity (Londres, Stevens \& Sons).

Hattenhauer, Hans (1987): Conceptos fundamentales del Derecho Civil (Traducc. Gonzalo Hernández, Barcelona, Ariel).

Heck, Philipp (1999): El problema de la creación del Derecho (Traducc. Manuel Entenza, Granada, Comares). 
Hernández Gil, Antonio (1988): Derecho de obligaciones (Madrid, Espasa-Calpe), tomo III de sus Obras Completas.

IONESCu, Octavian (1978): La notion de droit subjectif dans le Droit privé (Bruselas, Bruylant).

IRTI, Natalino (1973): La perfezione degli atti giuridici e il concetto di onere (Nápoles, Jovene).

JaRrosson, Charles (1987): La notion d'arbitrage (París, Librairie Générale de Droit et de Jurisprudence).

Jiménez MAnCHA, Juan Carlos (1999): La compensación de créditos (Madrid, Edersa).

KRAJEWSkI, Władysław (1977): Correspondence Principle and Growth of Science (Dordrecht, Reidel).

LACrUz, José Luis (2013): Elementos de Derecho Civil (Barcelona, Bosch), tomo II, vol. 1.

Larenz, Karl (1959): Derecho de obligaciones (Traducc. Jaime Santos Briz, Madrid, Revista de Derecho Privado), tomo I.

(2010): Metodología de la ciencia (Traducc. Marcelino Rodríguez Molinero, Barcelona, Ariel).

LeNOBLE, Jacques (Editor) (1990): La crise du juge (Bruselas-París, Bruylant-Librairie Générale de Droit).

LifANTE, Isabel (2002): "Dos conceptos de discrecionalidad jurídica", en: Doxa ( No 25), pp. 413-439.

(2006): "Poderes discrecionales", en: García Figueroa, Alfonso (Editor), Racionalidad y Derecho (Madrid, Centro de Estudios Políticos y Constitucionales), pp. 107-132.

LÓPEZ JACOISTE, José Javier (1976): "Sobre la aporía de la equivalencia contractual", en: AA.VV., Estudios Jurídicos en Homenaje al profesor Federico de Castro (Madrid, Tecnos), tomo II, pp. 833-847.

Martín Pallín, José Antonio (2010): ¿Para qué servimos los jueces? (Madrid, Los Libros de la Catarata).

MAURY, Jacques (1920): Essai sur le rôle de la notion d'équivalence en Droit civil française (París, Jouve).

MAZZARESE, Tecla (1996a): Forme di razionalità delle decisioni giudiziali (Turín, Giappichelli).

(1996b): "Lógica borrosa y decisiones judiciales: El peligro de una falacia racionalista" (Traducc. José Juan Moreso Mateos), en: Doxa (№ 19), pp. 201-228. 
MerLIN, Elena (1991): Compensazione e processo (Milán, Giuffrè).

Molina, Luis de (1981): La teoría del justo precio (Madrid, Edit. Nacional).

Moreso, José Juan (2012): "Derechos, deberes y discreción judicial", en SAIz Arnalz, Alejandro (Editor), Los derechos fundamentales de los jueces (Madrid, Marcial Pons), pp. 199-209.

Mosco, Luigi (1982): La resolución de los contratos por incumplimiento (Barcelona, Nereo).

MunNÉ, Frederic (2004): El arbitraje en la ley Nº 60/2003: una visión práctica para la gestión eficaz de conflictos (Barcelona, Experiencia).

NAtolı, Ugo (1975): "La regola della correttezza a l'attuazione del rapporto obbligatorio (art. 1.175 del CC)", en: AA.VV., Studi sulla buona fede (Milán, Giuffrè), pp. 119-130.

Nieto, Alejandro (2000): El arbitrio judicial (Barcelona, Ariel). (2005): Del arbitrio y de la arbitrariedad judicial (Madrid, lustel).

Ogayar, Tomás (1983): Efectos que produce la obligación bilateral. Doctrina jurisprudencial sobre los artículos 1.124 y 1.504 del Código Civil (Pamplona, Aranzadi).

Pérez, Antonio (1661): De iustitia et iure, et de restitutione et poenitentia (Lyon).

Pérez-Cruz, Agustín-Jesús (Director) (2011): Los nuevos retos del arbitraje en una sociedad globalizada (Madrid, Civitas).

Picod, Yves (1989): Le devoir de loyauté dans l'exécution du contrat (París, Librairie Générale de Droit et Jurisprudence).

PRADA, José M. (1968): "La onerosidad y gratuidad de los actos jurídicos", en: Anales de la Academia Matritense del Notariado, pp. 99-116.

Puig, Federico (1999): Tratado de Derecho Civil español (Madrid, Edit. Revista de Derecho Privado), tomo IV, vol. 1.

Quintana, Fernando (2001): Prudencia y justicia en la aplicación del Derecho (Santiago, Edit. Jurídica de Chile).

Rawls, John (2002a): Teoría de la justicia (Traducc. M. Dolores González Soler, Madrid, Fondo de Cultura Económica).

(2002b): Justicia como equidad. Materiales para una teoría de la justicia (Traducc. Miguel Ángel Rodilla, Madrid, Tecnos).

Rebuffa, Giorgio (1993): La funzione giudiziaria (Turín, Giappichelli).

Redondo, M. Cristina et al. (2009): Estado de Derecho y decisiones judiciales (Madrid, Fundación Coloquio Jurídico Europeo).

ReNTERíA, Adrián (2002): Discrecionalidad judicial y responsabilidad (México D. F., Fontamara). 
Romano, Geremia (1995): Interessi del debitori e adempimento (Nápoles, Edizioni Scientifiche Italiane).

Ross, Alf (2005): Sobre el Derecho y la justicia (Traducc. Genaro R. Carrió, Buenos Aires, Eudeba).

RugGiero, Roberto de (1929): Instituciones de Derecho Civil (Traducc. Ramón Serrano Suñer y José Santa Cruz, Madrid, Reus), tomo II.

RuIz, Ramón (2011): "El desplazamiento de la discrecionalidad del legislador al juzgador: causas y recelos", en: Anuario de Filosofía del Derecho (T. XXVII), pp. 187-208.

SalaniÉ, Bernard (1998): The Economic of Contracts (Cambridge, Mass., Londres, MIT Press).

SánChez-Blanco, Jaime (1952): "Onerosidad, gratuidad y causa", en: Revista de Derecho Privado (T. XXXVI), pp. 476-510.

San Miguel, Lis Paula (2003): La resolución del contrato por incumplimiento y modalidades de su ejercicio (Madrid, Colegio de Registradores de la Propiedad y Mercantiles de España).

(2011a): "La modernización del Derecho de Obligaciones y la resolución por incumplimiento en los ordenamientos español y chileno", en: DE LA MAZA, Í. (coord.), Incumplimiento contractual: nuevas perspectivas, Cuadernos de Análisis Jurídico, Colección de Derecho Privado ( ${ }^{\circ}$ VII) (Santiago de Chile, Universidad Diego Portales), pp. 107-170.

(2011b): "La resolución por incumplimiento en la Propuesta para la Modernización del Derecho de Obligaciones y Contratos: ¿lo mejor es enemigo de lo bueno?", en: Anuario de Derecho Civil (№ 4), pp. 1685-1724. Von SAvigny, Friedrich Karl (2005): Sistema del Derecho romano actual (Traducc. Jacinto Mesía y Manuel Poley, Granada, Comares).

Schapp, Wilhelm (1931): La nueva ciencia del Derecho (Traducc. José Pérez Bances, Madrid, Revista de Occidente).

SCHLESINGer, Piero (1959), voz "Compensazione (Dirirro civile)", en: Novissimo Digesto Italiano (vol. III) (Turín, UTET), pp. 722-726.

Seriaux, Alain (1985): "Le future contractuel", en: AA.VV., Le Droit et le futur. Travaux et recherches de I'Université de Droit, d'Économie et de Sciences Sociales de Paris (París, Presses Universitaires de France), pp. 77-90.

SPRY, Ian (2009): The Principles of Equitable Remedies. Injunctions, Specific Performance and Equitable Damages (Sydney-Londres, Sweet \& MaxwellThe Law Book Company Limited).

StegmülleR, Wolfgang (1976): The Structure and Dynamics of Theories (Berlín, Springer). 
Stone, Julius (1968): Human Law and Human Justice (Stanford, Stanford University Press).

TAPIA, Isabel (1988): La compensación en el proceso civil (Madrid, Trivium).

TerRé, Francois et al. (2009): Droit civil. Les obligations (París, Dalloz).

Tettenborn, Andrew M. (1984): An Introduction to the Law of Obligations (Londres, Butterworths).

TrebILCOCK, Michael J. (1997): The Limits of Freedom of Contract (Cambridge Mss., Harvard University Press).

VALPUESTA, Eduardo (1989): La prohibición de la arbitrariedad en el ámbito contractual privado (Pamplona, Universidad de Navarra).

VAn de KerChove, Michel y Ost, François (1997): El sistema jurídico entre orden y desorden (Traducc. Isabel Hoyo Sierra, Madrid, Facultad de Derecho de la Universidad Complutense de Madrid).

VAtTIER, Carlos (1980): Sobre la estructura de la obligación (Palma de Mallorca, Universidad de Palma de Mallorca).

(1986): voz "Obligaciones bilaterales", en: Nueva Enciclopedia Jurídica (Barcelona, Seix), tomo XVIII, pp. 34-38.

VILLA, Gianroberto (1993): Contratto e violazione di norme imperative (Milán, Giuffrè).

VISINTINI, Giovanna (1999): Trattato breve de la responsabilità civile: fatti illeciti, inadempimento, danno resarcibile (Padua, Cedam).

VON IHERING, R. (2008): La lucha por el Derecho (Traducc. Adolfo Posada, Granada, Comares).

(2011a): El espíritu del derecho romano en las diversas fases de su desarrollo (Traducc. Enrique Príncipe y Satorres, Granada, Comares), tomo III.

(2011b): El fin en el Derecho (Traducc. Diego Abad de Santillán, Granada, Comares). 